Cathia M. B. Serra 1 Cristianni A. Leal 2,5 Fabiano Figueiredo 3 Tânia M. Schubach 3 Rosemere Duarte 2,5 Cláudia M. A. U chôa 4 Roger Magno M. Silva 2,5

Maria de Fátima Madeira 2,5

\section{Leishmaniose tegumentar canina em Morada das Águias (Serra da Tiririca), Maricá, Rio de J aneiro, Brasil}

\author{
Canine tegumentary leishmaniasis in \\ Morada das Águias (Serra da Tiririca), \\ Maricá, Rio de J aneiro, Brazil
}

1 Faculdade de Veterinária, Universidade Federal Fluminense.

Rua Vital Brasil 64, Niterói, RJ 24230-340, Brasil. cathiaserrra@bol.com.br 2 Departamento de Ciências Biológicas, Escola Nacional de Saúde Pública, Fundação Oswaldo Cruz. Rua Leopoldo Bulhões 1480 , Rio de Janeiro, RJ 21041-210, Brasil. fmadeira@ensp.fiocruz.br 3 Departamento de Doenças I nfecciosas, Instituto de Pesquisa Clínica Evandro Chagas, Fundação Oswaldo Cruz. Av. Brasil 4365, Rio de Janeiro, RJ 21045-900, Brasil. 4 Departamento de Microbiologia e Parasitologia, Universidade Federal Fluminense. Rua Prof. Hernani de Mello 131, Niterói, RJ

24210-130, Brasil. 5 Departamento de Micro Imuno Parasitologia, Instituto de Pesquisa Clínica Evandro Chagas, Fundação Oswaldo Cruz. Av. Brasil 4365, Rio de Janeiro, RJ 21045-900, Brasil.
Abstract This is a report of canine tegumentary leishmaniasis in Morada das Águias (in the Serra da Tiririca mountain range), Maricá, Rio de Janeiro State, Brazil. A clinical, serological, and parasitological survey was performed in 83 dogs. Eleven (13.2\%) were positive on indirect immunofluorescence (IIF) and 30 (36.1\%) on enzyme-linked immunosorbent assay (ELISA). UIcerated cutaneous or mucosal lesions were observed in 18 ( $n=83 ; 21.7 \%)$ dogs. Leishmania was isolated from 11 of the animals. The disease occurrence and local occupational characteristics are discussed.

Key words Leishmania; Leishmaniasis; Dogs; Zoonoses

Resumo Descreve-sea ocorrência da leishmaniose tegumentar em cães da localidade de M orada das Águias (Serra da Tiririca), Maricá, Estado do Rio de Janei ro, Brasil. Foram avaliados 83 cães por meio de exames clínico, sorológi co e parasitológico. Os soros de $11(13,2 \%)$ animais foram reagentes à imunofluorescência indireta (IFI) e de $30(36,1 \%)$ ao ensai o imunoenzimático (ELISA). Úlceras cutâneas e ou mucosas foram observadas em 18 ( $n=83 ; 21,7 \%$ ) dos animais. Leishmania foi isolada de 11 cães. Discute-se a ocorrência da doença e a ocu pação da localidade.

Palavras-chave Leishmania; Leishmaniose; Cães; Zoonoses 


\section{Intro dução}

Nos últimos anos, em diversas regiões do Sudeste brasileiro, a leishmaniose tegumentar americana (LTA) tem ocorrido na forma de microepidemias relacionadas principal mente ao processo migratório com a ocupação de encostas em áreas periféricas urbanas e envolvendo no seu ciclo de transmissão animais domésticos, em especial, os cães ( $M$ arzochi \& M arzochi, 1994). Tal fato levou o Ministério da Saúde (MS, 2000) a considerar, nessas regiões, um novo padrão epidemiológico dessa zoonose.

O Município de Maricá (Rio de Janeiro) sofreu um processo de urbanização, iniciado na década de 40, por meio da fragmentação da terra das fazen das locais, alterando sua estrutura espacial e transformando-o em um município periurbano. Dessa forma, tornou-se integrado definitivamente à Região M etropolitana do Rio de Janeiro (Martins, 1986). Em Maricá, a ocorrência esporádica de casos humanos e caninos de LTA tem sido associada com a ocupação humana próximo às encostas (Horta et al., 1998; Madeira et al., 2001). Recentemente, foram notificados na Secretaria Municipal de Saúde de Maricá (SMS-Maricá) dois casos humanos de LTA ocorridos no Condomínio Morada das Águias, área situada junto à encosta da Serra da Tiririca, a qual foi considerada pela Organização das Nações Unidas para a Educação, a Ciência e a Cultura (UNESCO), em 1992, como parte integrante da Reserva da Biosfera da M ata Atlântica, após movimentos sociais de preservação ambiental, que culminaram na implantação do Parque Estadual da Serra da Tiririca. No entanto, apesar de todos esses esforços, sua paisagem natural já havia sido bastante alterada por desmatamentos sucessivos, que ainda acontecem e acarretam importantes desequilíbrios ambientais, favorecedores à instalação do ciclo peridoméstico da LTA.

O presente trabalho objetivou avaliar a ocorrência da LTA na população canina residente nesta localidade.

\section{Material e métodos}

Durante o período de agosto a dezembro de 2002 , foi realizado um censo da população canina por intermédio da visita domiciliar, casa a casa no Condomínio Morada das Águias.

A área estudada encontra-se situada no loteamento Morada das Águias, junto à encosta da Serra da Tiririca no Município de Maricá (Figura 1). Este localiza-se no Estado do Rio de Janeiro, tendo como limites os municípios de $\mathrm{Ni}$ terói, São Gonçalo, Itaboraí, Tanguá e Saquare- $\mathrm{ma}$, abrangendo uma área de $362,94 \mathrm{Km}^{2} \mathrm{com}$ uma população estimada em 2002 de 83.938 habitantes. Os indicadores demográficos do censo de 2000 revelaram em M aricá uma taxa de crescimento de 5,71\% e uma taxa de migração de 4,49\% (Anuário Estatístico do Rio de Janeiro, 2002).

Os cães foram clinicamente avaliados quanto à presença de lesões sugestivas de LTA, e na presença dessas, procedeu-se a biópsia, sendo os fragmentos submetidos à cultura para Leishmania. Amostras de sangue foram coletadas para o diagnóstico sorológico utilizando-se as técnicas de imunofluorescência indireta (IFI) e ensaio imunoenzimático (ELISA).

\section{Diagnóstico parasitológico}

Da borda da lesão foi retirado um pequeno fragmento, o qual foi imerso em solução salina contendo $1.000 \mathrm{U}$ I de penicilina $\mathrm{G}$ potássica

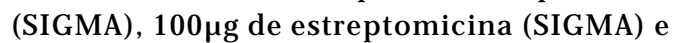
$50 \mu \mathrm{g}$ de 5 -fluorocitosina (SIGMA) por mililitro. Após 24 horas a $4^{\circ} \mathrm{C}$, os fragmentos foram seccionados e semeados em meio bifásico NNN (Novy, MacNeal e Nicolle)/Schneider's Insect Medium (SIGMA) contendo $10 \%$ de soro fetal bovino. O material foi incubado a $28{ }^{\circ} \mathrm{C}$ por um mês, sendo realizados exames semanais a partir do quinto dia.

\section{Diagnóstico sorológico}

- IFI: A reação de imunofluorescência indireta para a pesquisa de IgG foi realizada segundo a descrição do kit de IFI para diagnóstico da leishmaniose canina (Biomanguinhos/ FIOCRUZ/MS). Considerou-se como positivas amostras que apresentaram fluorescência em diluições iguais ou maiores que $1 / 40$.

- ELISA: O método utilizado teve como princípio a metodologia indireta para pesquisa de Ig total de cão, específico para antígenos de Leishmania (promastigotas de Leishmania braziliensis), previamente fixados em placa de poliestireno de fundo chato com 96 poços. Os soros foram diluídos a 1:20 em duplicata. A determinação de positividade baseou-se em leituras superiores ao cut off.

\section{Resultados}

Na área do condomínio, foram observados 72 residências e 116 cães, incluindo dois animais errantes, 14 avistados em casas fechadas e 17 

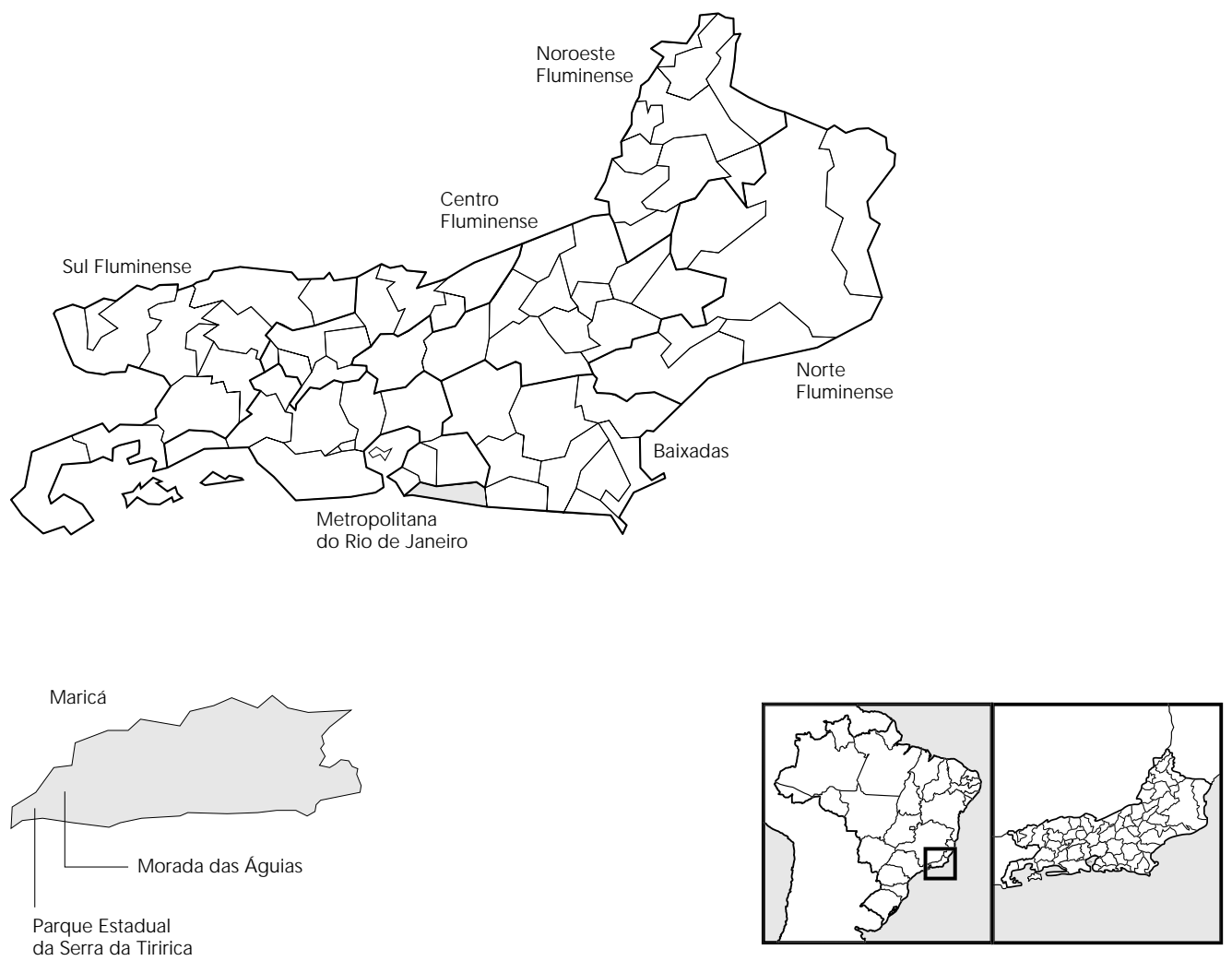

Fonte: Mapas adaptados do Anuário Estatístico do Rio de J aneiro, 2002.

filhotes com idade inferior a três meses, que não foram incluídos no estudo. Cães estavam presentes em 40 residências $(55,5 \%)$, sendo que dessas, foram visitadas 33 onde 83 cães foram avaliados. Os soros de $11(13,2 \%)$ animais reagiram à IFI e de $30(36,1 \%)$ ao ELISA. Úlceras cutâneas e ou mucosas foram observadas em 18 ( $n=83 ; 21,7 \%$ ) dos animais, sendo em 12 únicas e em 6 múltiplas, localizadas no paviIhão auricular, focinho, face, membro posterior, bolsa escrotal e mucosa nasal. A cultura dos fragmentos foi realizada em 16 cães, sendo obtido o isolamento de Leishmania em 11. Durante o período do estudo, mais um caso humano foi notificado. A maioria dos casos caninos confirmados pelo isolamento parasitário ocorreu na rua da encosta da referida Serra, bem como os três casos humanos.
A transformação de Maricá da condição de um município rural para um município periurbano ocorreu por meio dos loteamentos que foram feitos em seu território, acarretando profundas alterações sócio-econômico-espaciais, com destaque para a dependência econômica desse parcelamento de terras e a introdução de uma nova população de origem urbana (M artins, 1986). Nesse contexto, encontra-se atualmente M orada das Águias, área localizada numa região do município que vem sofrendo expressiva derrubada da mata junto à encosta da Serra da Tiririca para a instalação de moradias de classe média, principalmente com objetivo de veraneio. Verifica-se também, que embora o crescimento populacional do Estado do Rio de Janeiro tenha sido pequeno nos últimos anos, o mesmo não ocorreu em alguns de seus mu- 
nicípios, principalmente naqueles da faixa litorânea, como Maricá, nos quais foram observadas as maiores taxas de crescimento populacional e migratório principalmente relacionadas à expansão da atividade turística e de veraneio (Anuário Estatístico do Rio de Janeiro, 2002). Kawa \& Sabroza (2002), ao analisarem a espacialização da leishmaniose tegumentar na Cidade do Rio de Janeiro, verificaram que as taxas de incidência média foram muito mais elevadas onde havia maiores taxas de crescimento populacional e que, portanto, a dinâmica do processo endêmico-epidêmico da leishmaniose tegumentar no Município do Rio de Janeiro estaria associada aos processos particulares de ocupação. Situação semelhante poderia estar acontecendo em Maricá, e o elevado número de casos caninos verificados em Morada das Á- guias ser conseqüência de uma ocupação desordenada da terra, acarretando abrupta modificação da paisagem original, favorecendo a ocorrência do efeito marginal, com formação do ecótono, permitindo a adaptação de flebotomíneos ao peridomicílio e tornando homens e cães fonte alimentar de fácil acesso. Apesar da ocorrência da doença canina na região, não é possível, ainda, incriminá-los pelos casos humanos. A presença de animais silvestres como gambá, ouriço, rato do mato, cuíca, entre outros, junto às casas foi relato constante dos moradores. Estudos são necessários visando a conhecer a fauna flebotomínica local, bem como elucidar o papel dos diversos animais no ciclo de transmissão da doença.

\section{Referências}

ANUÁRIO ESTATÍSTICO DO ESTADO DO RIO DE JANEIRO, 2002. Demografia. 3 Julho 2003 ঝttp:// www.cide.rj.gov.br/produtos/anuario 02/ principal.htm>.

HORTA, F. T.; SERRA, C. M. B.; MADEIRA, M. F.; MACEDO, R. M. S.; DUARTE, R. \& PACHECO, R. S., 1998. Epidemiological study of Canine Tegumentary Leishmaniasis in Inoã District (Maricá Municipality, Rio de Janeiro, Brasil). Memórias do Instituto Oswaldo Cruz, 93(Sup. 2):113.

KAWA, H. \& SABROZA, P. C., 2002. Espacialização da leishmaniose tegumentar na cidade do Rio de Janeiro. Cadernos de Saúde Pública, 18:853-865.

MADEIRA, M. F.; UCHÔA, C. M. A.; MAGALHÃES, C. M.; DUARTE, R.; MACEDO, R. M. M.; FIGLIOULO, L. F.; LEAL, C. A. \& SERRA, C. M. B., 2001. Avaliação da circulação da Leishmaniose no Município de Maricá-Rio de Janeiro. Um estudo de três anos. Revista da Sociedade Brasileira de Medicina Tropical, 34(Sup. 1):190-191.
MARTINS, A. M. M., 1986. O Parcelamento da Terra no Município de Maricá, Estado do Rio de Janeiro. Dissertação de Mestrado, Rio de Janeiro: Instituto de Geociências, Universidade Federal do Rio de Janeiro.

MARZOCHI, M. C. A. \& MARZOCHI, K. B., 1994. Tegumentary and visceral leishmaniasis in Brazil Emerging anthropozoonosis and possibilities for their control. Cadernos de Saúde Pública, 10:359375.

MS (Ministério da Saúde), 2000. Manual de Controle da Lei shmaniose Tegumentar Americana. Brasília: Centro Nacional de Epidemiologia, Fundação Nacional de Saúde, Ministério da Saúde.

Recebido em 26 de março de 2003

Versão final reapresentada em 21 de julho de 2003

Aprovado em 31 de julho de 2003 